\title{
Few-cycle nonlinear mid-IR pulse generated with cascaded quadratic nonlinearities
}

\author{
Bache, Morten; Liu, Xing; Zhou, Binbin
}

Link to article, DOI:

10.1109/CLEOE-IQEC.2013.6801091

Publication date:

2013

Document Version

Publisher's PDF, also known as Version of record

Link back to DTU Orbit

Citation (APA):

Bache, M., Liu, X., \& Zhou, B. (2013). Few-cycle nonlinear mid-IR pulse generated with cascaded quadratic nonlinearities. Abstract from 2013 Conference on Lasers \& Electro-Optics Europe \& the International Quantum Electronics Conference (CLEO/Europe-IQEC), Munich, Germany. https://doi.org/10.1109/CLEOEIQEC.2013.6801091

\section{General rights}

Copyright and moral rights for the publications made accessible in the public portal are retained by the authors and/or other copyright owners and it is a condition of accessing publications that users recognise and abide by the legal requirements associated with these rights.

- Users may download and print one copy of any publication from the public portal for the purpose of private study or research.

- You may not further distribute the material or use it for any profit-making activity or commercial gain

- You may freely distribute the URL identifying the publication in the public portal

If you believe that this document breaches copyright please contact us providing details, and we will remove access to the work immediately and investigate your claim. 


\title{
Few-cycle nonlinear mid-IR pulse generated with cascaded quadratic nonlinearities
}

\author{
Morten Bache ${ }^{1}$, Xing Liu ${ }^{1}$, and Binbin Zhou ${ }^{1}$
}

${ }^{1}$ Technical University of Denmark, DTU Fotonik, Department of Photonics Engineering, DK-2800 Kgs. Lyngby, Denmark

Generating few-cycle energetic and broadband mid-IR pulses is an urgent current challenge in nonlinear optics. Cascaded second-harmonic generation (SHG) gives access to an ultrafast and octave-spanning self-defocusing nonlinearity: when $\Delta k L \gg 2 \pi$ the pump experiences a Kerr-like nonlinear index change $\Delta n=n_{\text {casc }} I$, where $n_{\text {casc }} \propto-d_{\text {eff }}^{2} / \Delta k$, and $d_{\text {eff }}$ is the effective quadratic nonlinearity. Due to competing material nonlinearities $n_{\text {Kerr }}$ the total nonlinear refractive is $n_{\text {cubic }}=n_{\text {casc }}+n_{\text {Kerr }}$. Interestingly $n_{\text {cubic }}$ can become negative (self-defocusing), elegantly avoiding self-focusing problems, and making it possible to excite solitons with normal dispersion [1].
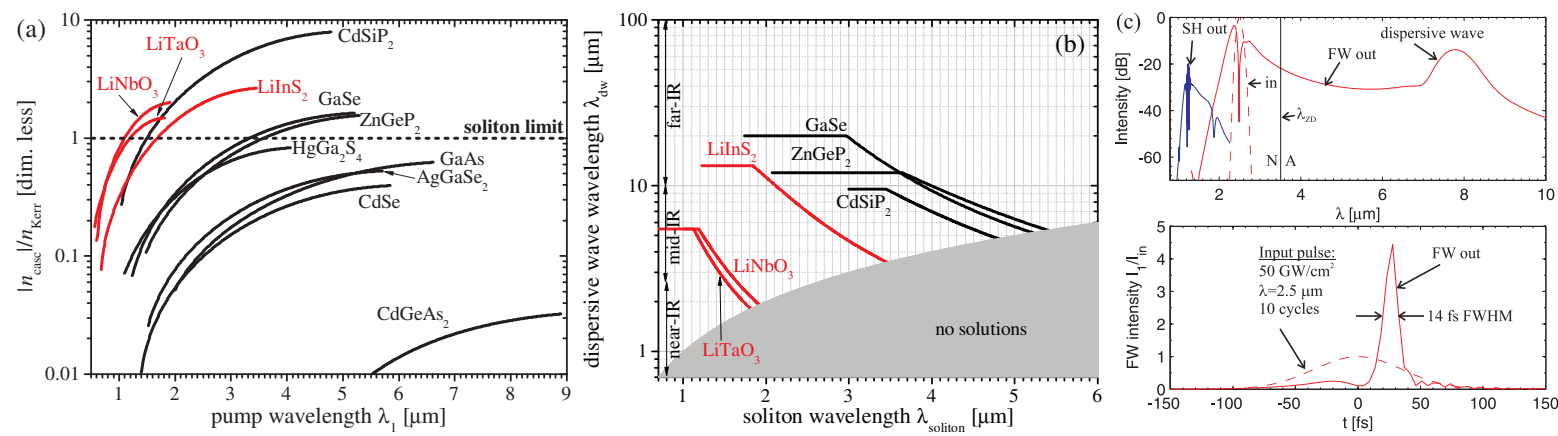

Figure 1. (a) FOM $\left|n_{\text {casc }}\right| / n_{\text {Kerr }}$ for type 0 cascaded SHG using dielectric (red) and semiconductor (black) materials, with $n_{\text {casc }}=-2 \omega_{1} d_{\text {eff }}^{2} / c^{2} \varepsilon_{0} n^{2}\left(\omega_{1}\right) n\left(\omega_{2}\right) \Delta k$ and $n_{\text {Kerr }}(\omega)=K^{\prime} G_{2}\left(\hbar \omega / E_{g}\right) \sqrt{E_{p}} / n^{2}(\omega) E_{g}^{4}$, with the linear index $n(\omega)$, the band gap energy $E_{g}, K^{\prime}=7.3 \times 10^{-9} \mathrm{eV}^{3.5} \mathrm{~m}^{2} / \mathrm{W}$ in dielectrics and $K^{\prime}=$ $14.0 \times 10^{-9} \mathrm{eV}^{3.5} \mathrm{~m}^{2} / \mathrm{W}$ in semiconductors, $E_{p}=21 \mathrm{eV}$ is a constant. A FOM $>1$ is required to excite solitons. (b) The DW phase-matching curves. (c) Numerical simulation of a 10-cycle $\lambda=2.5 \mu \mathrm{m}$ and $I_{\text {in }}=$ $50 \mathrm{GW} / \mathrm{cm}^{2}$ pulse propagated $11 \mathrm{~mm}$ in a LiInS 2 crystal. 'A' and 'N' mark anomalous and normal dispersion.

Historically, critical (type I) cascaded SHG has been used. Recently we showed experimentally generation of strong and octave-spanning cascaded nonlinearities from a noncritical (type 0 ) interaction even without quasiphase matching (QPM) [2]. This allows for excitation of few-cycle self-defocusing solitons at the pump wavelength, generation of octave-spanning supercontinua [2] and creation of long-wavelength Cherenkov radiation [3]. "Standard" type 0 mid-IR crystals have huge $d_{\text {eff }}$, but are often overlooked because of a large $\Delta k$ value which cannot be reduced (as QPM methods are not developed or applicable). This limits the strength of $n_{\text {casc }}$ so it is crucial to understand whether regimes with $n_{\text {cubic }}<0$ can be found. Calculating the Kerr nonlinearity from the twoband model, Fig. 1(a) shows a figure-of-merit FOM $=\left|n_{\text {casc }}\right| / n_{\text {Kerr }}$; self-defocusing solitons require FOM $>1$. $\mathrm{LiNbO}_{3}$ and $\mathrm{LiTaO}_{3}$ have an FOM $>1$, but at around $\lambda=2 \mu \mathrm{m}$ the GVD changes sign and becomes anomalous (at this point the curves are terminated). Here the chalcogenide $\mathrm{LiInS}_{2}$ and the semiconductors GaSe, $\mathrm{CdSiP}_{2}$ and $\mathrm{ZnGeP}_{2}$, which have large band gaps and large $d_{\text {eff }}$, come into play with an FOM $>1$ for $\lambda>2 \mu \mathrm{m}$. Instead for e.g. $\mathrm{CdGeAs}_{2}$, its large $d_{\text {eff }}$ is counteracted by a very small band gap, giving a too large $n_{\text {Kerr }}$ due to the $E_{g}^{-4}$ scaling. None of the crystals with FOM $>1$ support self-defocusing solitons beyond $\lambda=5.5 \mu \mathrm{m}$. However, once excited the soliton will shed radiation through optical Cherenkov radiation to a linear dispersive wave (DW) in the anomalous dispersion regime $\lambda>\lambda_{\mathrm{ZD}}$. This can cover the long-wavelength range of the mid-IR. Fig. 1(b) shows the DW phase-matching curve $k_{1}(\omega)=k_{1}\left(\omega_{\text {sol }}\right)-\left(\omega-\omega_{\text {sol }}\right) / v_{g \text {,sol. }}$. In Fig. 1(c) a numerical simulation of $\mathrm{LiInS}_{2}$ shows that a 10-cycle input pulse at $2500 \mathrm{~nm}$ is soliton-compressed after $11 \mathrm{~mm}$ propagation to few-cycle duration. The soliton then generates a DW in the linear range (anomalous dispersion regime, $\lambda>3.5 \mu \mathrm{m}$ ), peaking at $\lambda=8 \mu \mathrm{m}$. This DW is very broadband and by isolating it with the equivalent of a long-pass filter we checked that it is a few-cycle pulse with excellent quality. The frequency conversion process is efficient, app. 10\%. Much like what the near-IR for LN [2,3], upon further propagation the soliton will fission into minor soliton pairs, each coupling to a dispersive wave in the anomalous dispersion regime. This will give a stronger peak around $\lambda=8 \mu \mathrm{m}$ but the coherence and quality drops. Eventually a very broadband supercontinuum will form across the spectrum.

\section{References}

[1] X. Liu, L.-J. Qian, and F. W. Wise, "High-energy pulse compression by use of negative phase shifts produced by the cascaded $\chi^{(2)}: \chi^{(2)}$ nonlinearity," Opt. Lett. 24, 1777-1779 (1999); S. Ashihara, J. Nishina, T. Shimura, and K. Kuroda, "Soliton compression of femtosecond pulses in quadratic media," J. Opt. Soc. Am. B 19, 2505-2510 (2002).

[2] B. B. Zhou, A. Chong, F. W. Wise, and M. Bache, "Ultrafast and Octave-Spanning Optical Nonlinearities from Strongly Phase-Mismatched Quadratic Interactions," Phys. Rev. Lett. 109, 043902 (2012).

[3] M. Bache, O. Bang, B. B. Zhou, J. Moses, and F. W. Wise, "Optical Cherenkov radiation in ultrafast cascaded second-harmonic generation," Phys. Rev. A 82, 063806 (2010); "Optical Cherenkov radiation by cascaded nonlinear interaction: an efficient source of few-cycle energetic near- to mid-IR pulses,” Opt. Express 19, 22 557-22 562 (2011). 